\section{Questión}

Periodismo / Comunicación ISSN 1669-6581
- Av. $44 \mathrm{~N}^{\circ} 676,1^{\circ}$ piso

CP 1900 - La Plata - Argentina

www.perio.unlp.edu.ar/question

INCIDENCIAS DEL COVID-19 EN ECUADOR

Lic. Inés de la Luz Bajaña Mendieta

DOI: https://doi.org/10.24215/16696581e321

\title{
INCIDENCIAS DEL COVID-19 EN ECUADOR
}

\section{INCIDENTS OF COVID-19 IN ECUADOR}

\author{
Lic. Inés de la Luz Bajaña Mendieta / inesluzbajana18@gmail.com \\ Inès de la Luz Bajaña Mendieta Licenciada en Ciencias de la Comunicación, Periodista y Locutora Ha realizado \\ producciones audiovisuales y gráficas. Docente de la Universidad Técnica Estatal de Quevedo (UTEQ). Ecuador. \\ Doctoranda Doctorado en Comunciación FPCS-UNLP
}

Las epidemias forman parte de la historia de la humanidad, han sido compañeras habituales de pueblos y civilizaciones dejando devastación y dolor. La pandemia del COVID-19 ha trastocado los cimientos de la sociedad del siglo XXI y cuestiona a nivel global los sistemas sanitarios, la economía mundial planteando nuevos retos éticos frente a las formas de cómo combatir este virus de manera efectiva. Ecuador es uno de los países de América Latina más golpeado por el COVID-19, actualmente el contagio comunitario aqueja a las Provincias de Guayas, Pichincha, Los Ríos, Manabí, El Oro y Azuay. Según el último reporte del Ministerio de Salud actualizado hasta la mañana del miércoles 29 de abril de 2020. Los casos confirmados de Covid-19 en Ecuador ascienden a 24.675 estas cifras fueron confirmadas en cadena nacional por Alexandra Ocles, Directora del Servicio Nacional de Gestión de Riesgos.

Ecuador cuenta con cuatro tipos de cifras oficiales relacionadas con fallecimientos por covid-19 u otras causas: El primer registro lo lleva El Ministerio de Salud Pública (MSP) que maneja en sus informes diarios un primer reporte de número de muertos confirmados. En este grupo están aquellos a los que se les tomó una muestra y salieron positivos, pero no lograron vencer la enfermedad. El segundo registro de la cartera de Estado se denomina: "fallecido probable", al cual no se tomó una muestra y no tuvo diagnóstico de la enfermedad y, por tanto, está en proceso de investigación y verificación para concluir si su causa de defunción fue por covid-19. La tercera estadística corresponde al número de defunciones del primer trimestre del 2020 por 
todas las causas en las nueve zonas, en las que está dividido el Ecuador, el desglose de defunciones por provincias se compara entre enero y la primera quincena de abril del 2018, 2019 y 2020. El cuarto registro de datos disponible es del Instituto Nacional de estadísticas y Censos (INEC), que tiene datos por provincias y cantones del $2018 \mathrm{y}$, cifras provisionales hasta la fecha.

La pandemia en Ecuador aumentó de forma exponencial, un informe publicado por The New York Times revela que la epidemia ha dejado una cifra de fallecimientos en Ecuador que es al menos 15 veces más alta que la cantidad oficial reportada por el gobierno. Los números sugieren que el país sudamericano sufre uno de los peores brotes del mundo, las cifras reflejan la magnitud del daño que el virus puede hacerle a los países en desarrollo, donde rápidamente puede llegar a saturar los sistemas de salud e incluso la capacidad del gobierno de llevar el registro de cuántas personas sucumben a causa del virus. La parte más sensible y traumatizante de esta tragedia es no poder darle el último adiós a un ser querido. Durante esta emergencia fallecieron pacientes que no recibieron tratamiento médico por otras enfermedades , el sistema de salud colapsó , así como también los servicios funerarios que no se daban abasto para atender a la población afectada, originando un impacto social de gran envergadura ,sobretodo en Guayaquil epicentro de la pandemia ,ante lo cual la Alcaldesa de Guayaquil Cinthya Viteri calificó que lo vivido por la emergencia sanitaria en la urbe se compara con lo ocurrido en Hiroshima: "Una bomba inesperada en una ciudad pacífica ".

El reporte diario de los medios de comunicaciones informa de aquellos cuyos cadáveres abandonados en las calles, de los que yacían en sus casas sin ser retirados por varios días o de los que debieron esperar hasta semanas para ser cremados. Esta odisea sumada a la corrupción de muchos servidores que extorsionaban con pagos a los deudos para buscar a su familiar en las fundas que los contenían, ubicados en los depósitos lúgubres de los hospitales, sin identificación, hacía que esta tarea sea más dolorosa. Ante esta realidad surge una iniciativa emprendida por La Asociación de Cartoneros que en conjunto con actores privados, donó en Guayaquil, dos mil ataúdes de cartón corrugado ante la falta de ataúdes por la crisis sanitaria, sin bien fue una acción solidaria género repudio nacional.

El COVID-19 encontró a Ecuador endeudado y sin recursos para hacer frente a la pandemia y a los problemas conexos sumados por el aislamiento, estancamiento de la producción y el casi 
inexistente comercio, la caída del precio del petróleo. En tales circunstancias, atender la crisis sanitaria, asistir a la población vulnerable que no tiene ingresos y evitar que pierdan el empleo quienes aún lo conservan es una tarea enorme. El presidente de la República, Lenin Moreno, llama a la unidad nacional y apela a la solidaridad de todos los ecuatorianos presentando a la Asamblea Nacional El proyecto de Ley Orgánica de Apoyo Humanitario para combatir la crisis sanitaria derivada del COVID-19. El principal objetivo: hacerle frente a la crisis de salud, económica y social que atraviesa el país, producto de la pandemia. EL jueves 30 de abril inicia el debate en el pleno de la Asamblea Nacional que modifica sustancialmente la propuesta del Ejecutivo en cuanto a la tabla de aportaciones, entre las principales reformas consta: subir de \$ 500 a $\$ 720$, el monto base del salario, sobre el cual los trabajadores con relación de dependencia, tanto del sector público como privado, deberán pagar una contribución humanitaria. Para el aporte se tomará en cuenta el ingreso neto mensual. De manera progresiva se establece el aporte, que empieza con \$6, por nueve meses, para aquel trabajador que gane $\$ 720$ mensuales hasta $\$ 66.102$ para quien gane un sueldo superior a los \$250.001 mensuales. No se considerará para el aporte, la décima tercera ni la décima cuarta remuneraciones ni otros beneficios sociales legalmente establecidos, percibidos mensualmente, restando el aporte personal a la seguridad social. Los empleadores actuarán como agentes de retención de esta contribución y la pagarán de forma mensual en el mes inmediato siguiente al que corresponda la remuneración. Ante la opinión ciudadana esta Ley no es otra cosa que un nuevo impuesto que la burocracia económica pretende crear en el más duro momento familiar, económico, sanitario y social de la historia ecuatoriana.

El sistema sanitario tendrá que orientar su estrategia en mantener las medidas preventivas de higiene, nutrición y distanciamiento social, con una educación para la salud vía un ejército de promotores, los propios individuos afectados, bajo una orientación médica en distintos niveles de formación y distancia. Los trabajadores de los servicios básicos, agua, electricidad, recolección de basura, seguridad, educación, atención de salud, comunicación y en la producción y distribución de alimentos, son los héroes de esta tragedia, el mejor tributo que podemos devolver a nuestros mártires que ofrendaron sus vidas, es cambiar este sistema sanitario obsoleto por un sistema sanitario moderno, vanguardista y justo, donde los médicos, enfermeros y terapistas, sean bien remunerados Ojalá esta experiencia en enfrentar esta 
pandemia nos deje una enseñanza, que las prioridades de un Estado son la salud y la educación, para poder desarrollarse el país y alcanzar el primer mundo.

\section{El avance de la curva de contagio en Ecuador}

\section{Total casos 24934 en el país: PCR: 16404 / Pruebas rápidas: 8530}

Actualizado al 30 de abril

Casos totales

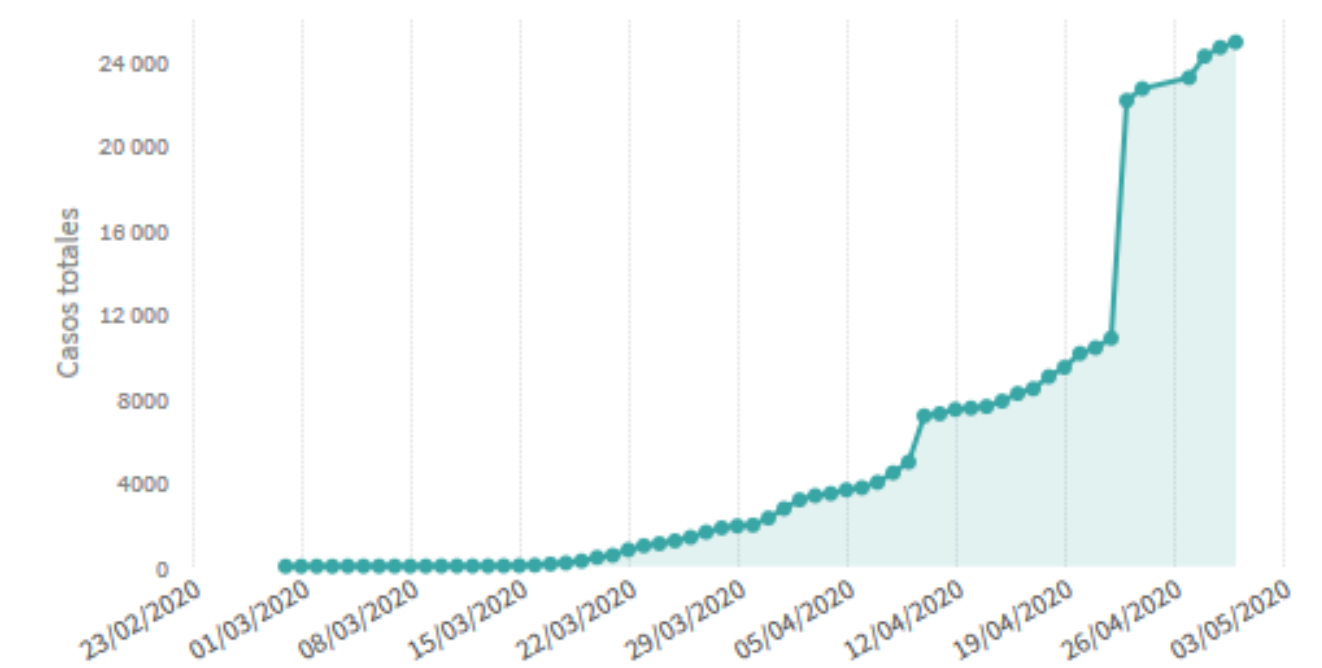

\section{NOTICIAS ENLACES:}

http://www.tvc.com.ec/actualidad/417-profesionales-de-la-salud-dieron-positivo-paracoronavirus -57497

http://www.tvc.com.ec/actualidad/familia-guayaquilena-se-recupera-del-covid-19-57626 https://www.expreso.ec/actualidad/coronavirus-testimonios-tratar-controlado-covid19-8848.html https://www.ecuavisa.com/articulo/noticias/nacional/593821-grupos-lgbti-reclaman-atencionsocial-del-gobierno-covid-19

http://www.tvc.com.ec/actualidad/se-investigara-el-mal-manejo-de-los-cadaveres-en-casa-desalud-57578

http://www.tvc.com.ec/actualidad/en-guayaquil-personas-esperan-turnos-en-cementerios-parasepultar-a-sus-familiares- 57467 
http://www.tvc.com.ec/actualidad/intentan-trasladar-a-cadaver-como-pasajero-en-vehiculo57628

http://www.tvc.com.ec/actualidad/ciudadanos-cuestionan-ingreso-de-contenedores-a-

cementerio-en-guayas-57627

http://www.tvc.com.ec/actualidad/ataudes-abandonados-en-las-calles-de-guayaquil-alarman-ala-ciudadania-57465

http://www.tvc.com.ec/actualidad/decenas-de-personas-pugnan-por-recarga-de-tanques-deoxigeno-en-guayaquil-57579

http://www.tvc.com.ec/actualidad/guayaquil--fuerza-conjunta-ha-levantado-500-cadaveres-

57537

https://cnnespanol.cnn.com/2020/04/06/en-ecuador-reparten-ataudes-de-carton-ante-laescasez-de-los-de-madera/

https://www.youtube.com/watch?v=p9ahc7eXcfg\&feature=emb_title

https://www.primicias.ec/noticias/sociedad/paciente-cero-coronavirus-ecuador/

https://lahora.com.ec/losrios/noticia/1102317070/se-duplican-los-contagios

http://www.tvc.com.ec/actualidad/confinamiento-en-ecuador-se-extiende-una-semana-mas-

57635

https://www.eluniverso.com/noticias/2020/03/25/nota/7794591/coronavirus-ecuador-controlesmilitares

https://www.extra.ec/actualidad/medicos-trabajo-arriesgado-coronavirus-ecuador-LE3402728 


\section{FOTOGRAFİS}

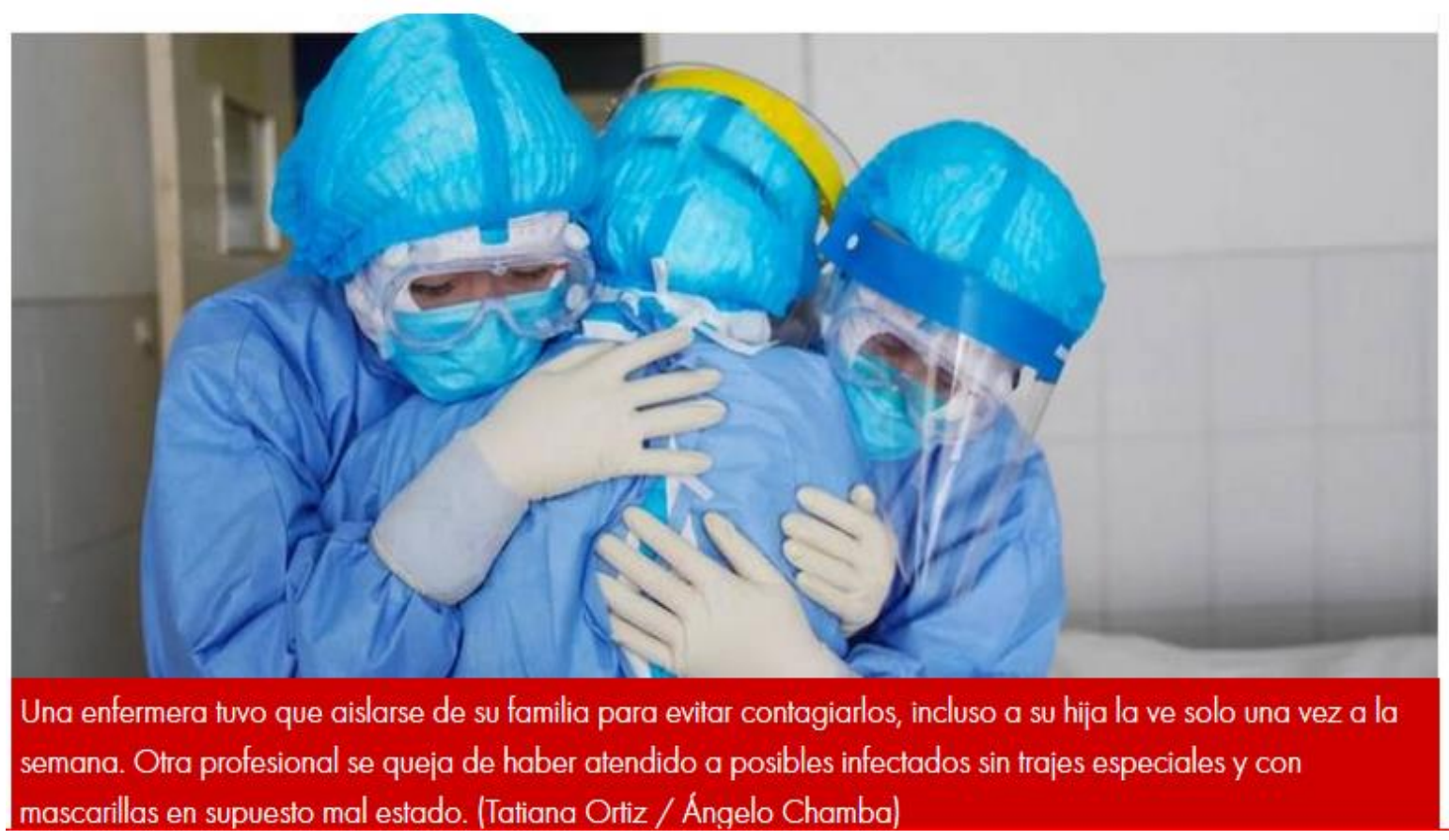




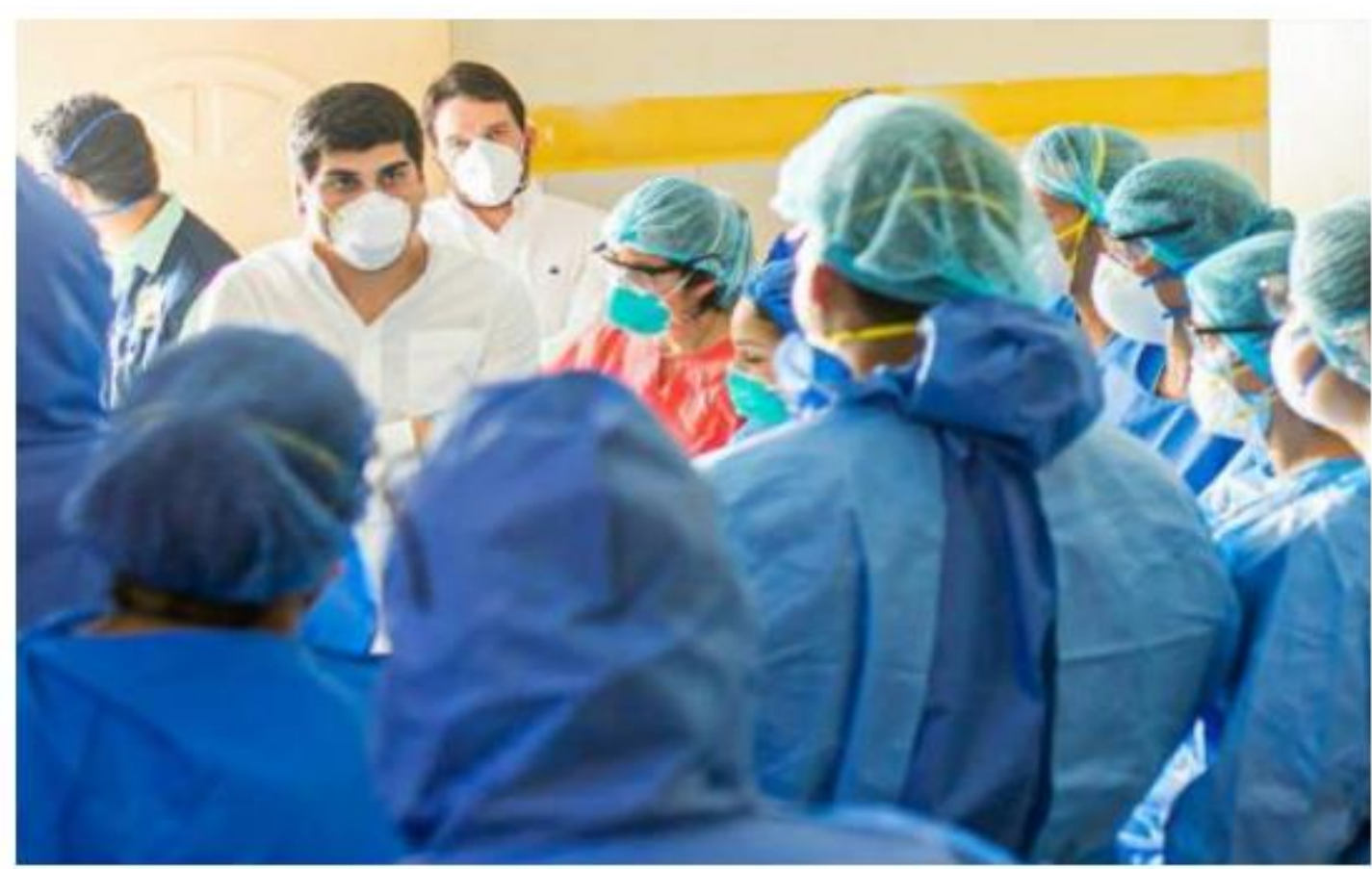

El personal del Hospital Martín Icaza, de Babahoyo, se reunió con el Vicepresidente. Foto. Cortesia Vicepresidencia 


\section{(c) $\underset{B \mathrm{BY} \text { NC SA }}{(\text { SA }}$}

Esta obra está bajo una Licencia Creative Commons

Atribución-NoComercial-Compartir Igual 4.0 Internacional
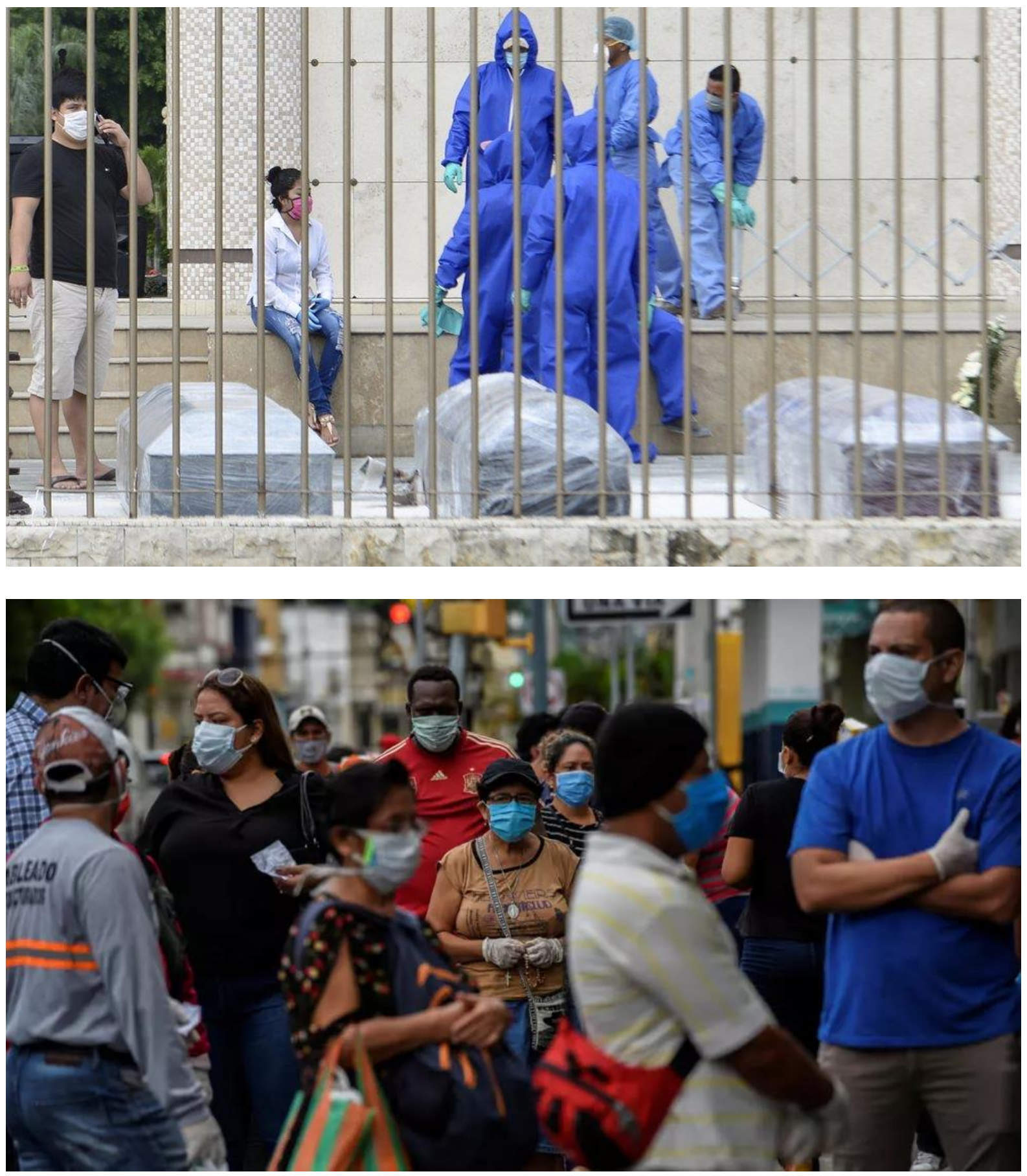

Question/Cuestión, Informe Especial Incidentes III, mayo 2020. ISSN 1669-6581

IICom (Instituto de Investigaciones en Comunicación)

Facultad de Periodismo y Comunicación Social

Universidad Nacional de La Plata 


\section{(c) $\underset{\mathrm{BY} \text { NC SA }}{(\text { (1) }}$}

Esta obra está bajo una Licencia Creative Commons

Atribución-NoComercial-Compartir Igual 4.0 Internacional

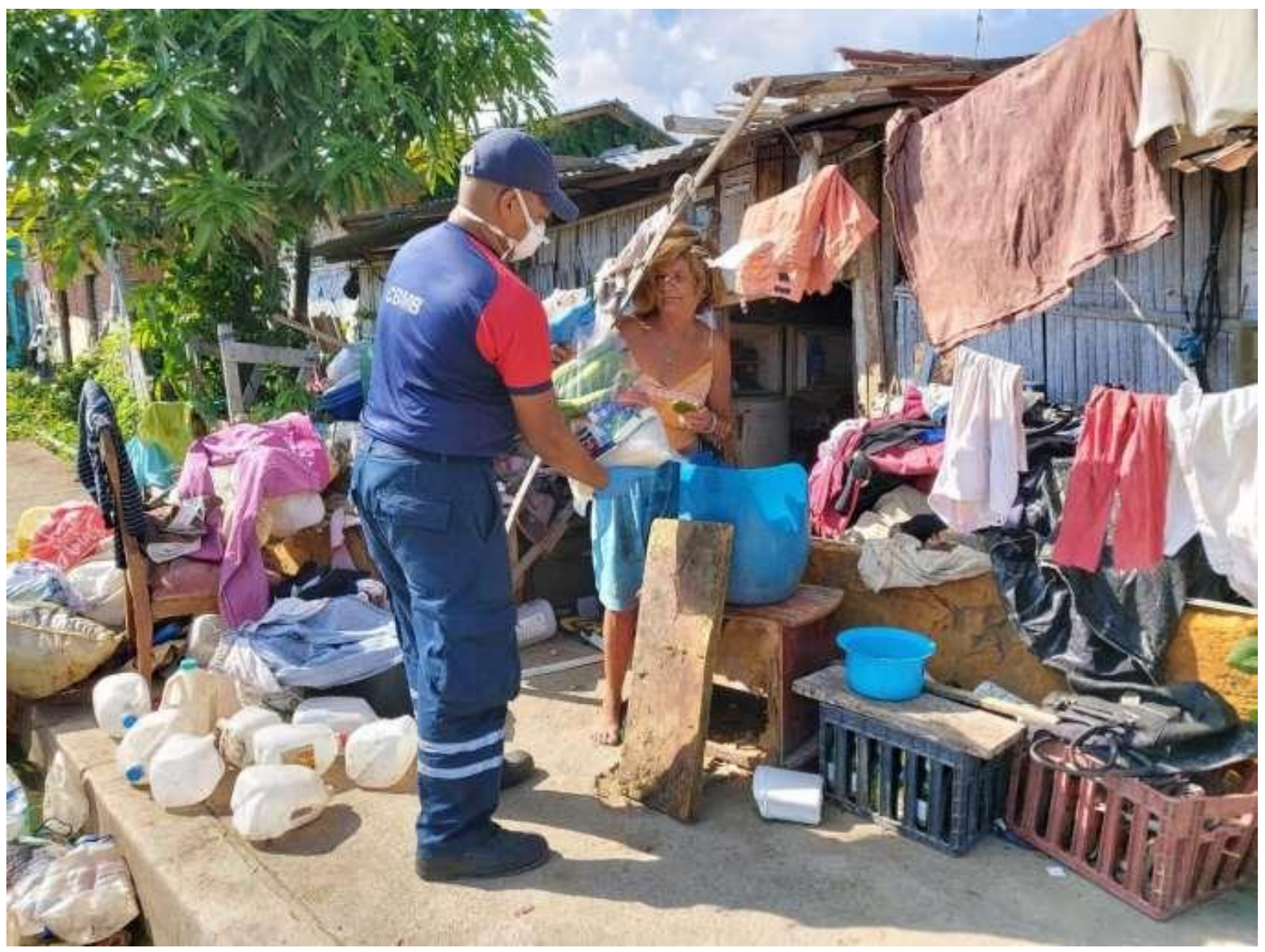



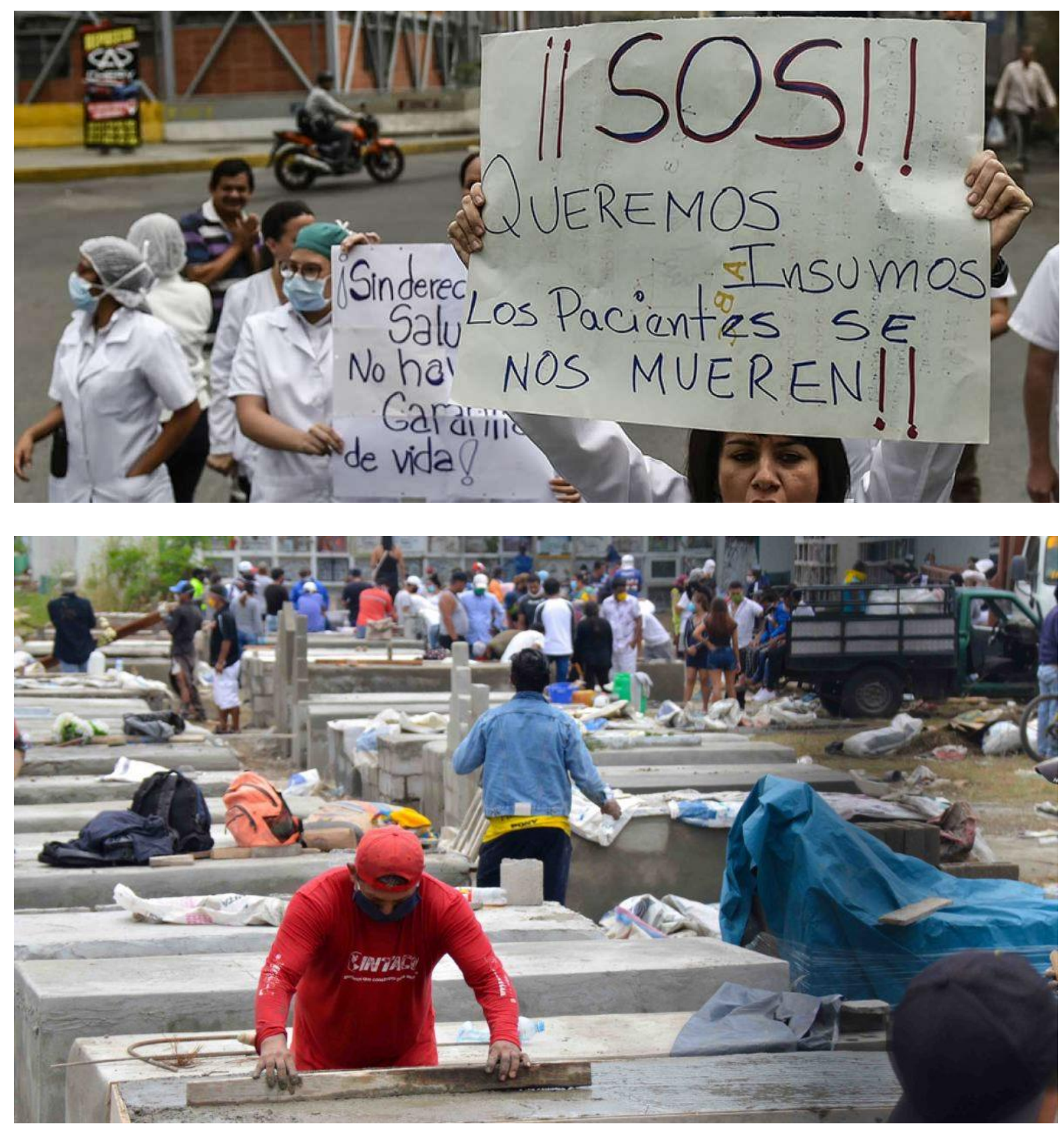


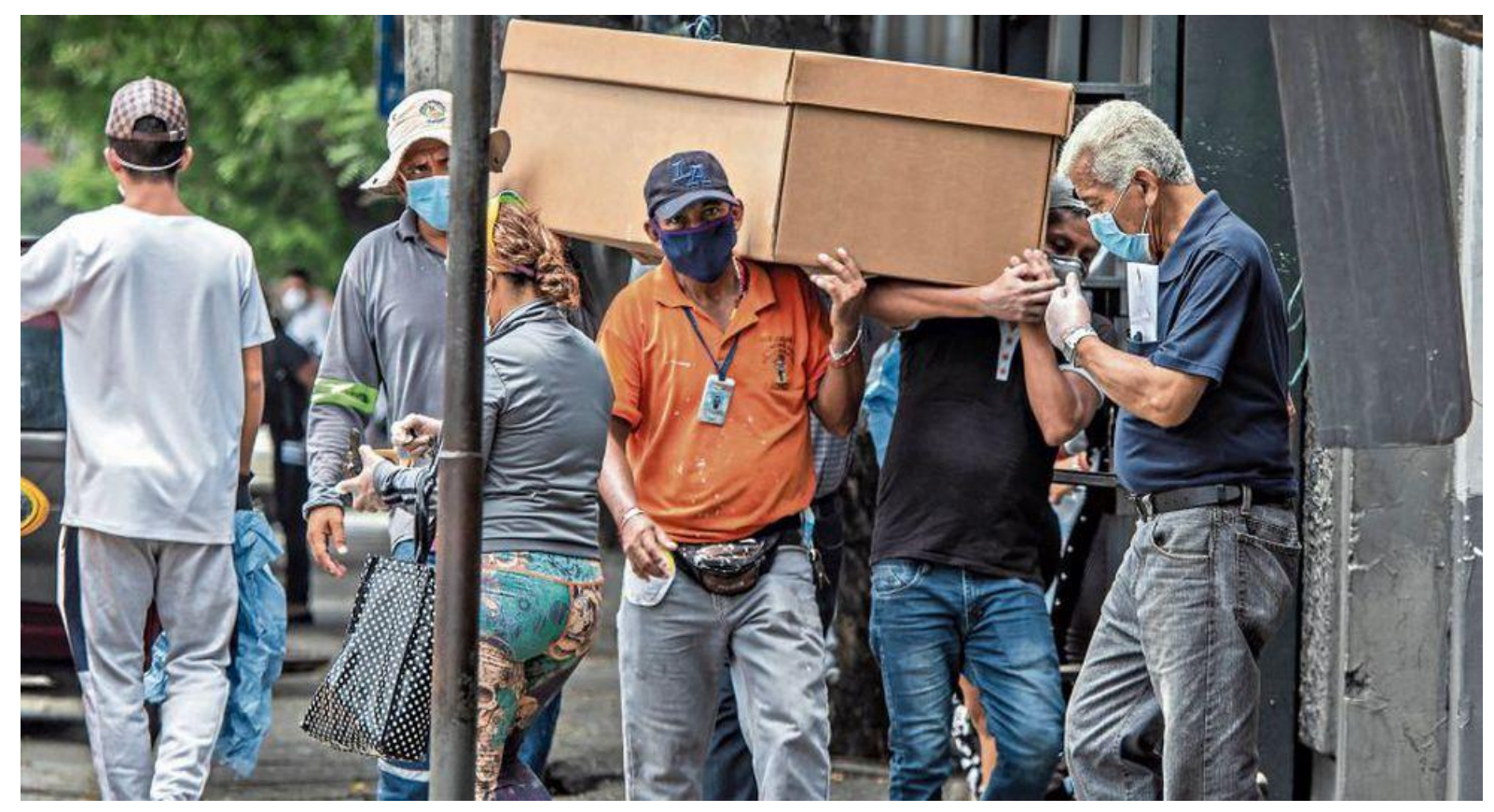




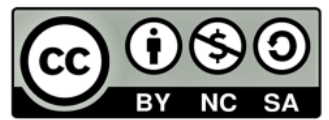

Esta obra está bajo una Licencia Creative Commons

Atribución-NoComercial-Compartir Igual 4.0 Internacional

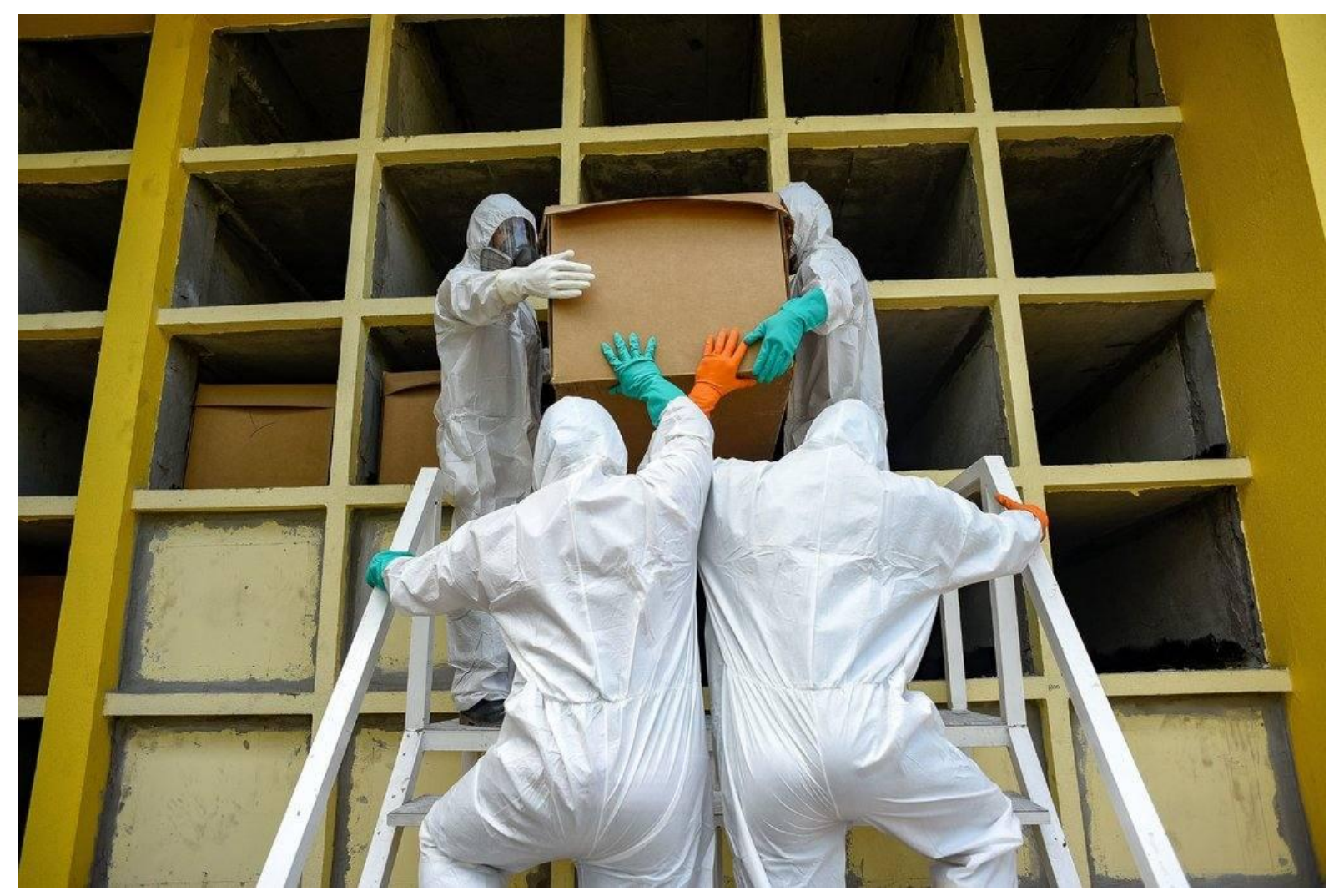




\section{(c) $\underset{\mathrm{BY} N \mathrm{NC} \mathrm{SA}}{(1)}$}

Esta obra está bajo una Licencia Creative Commons

Atribución-NoComercial-Compartir Igual 4.0 Internacional

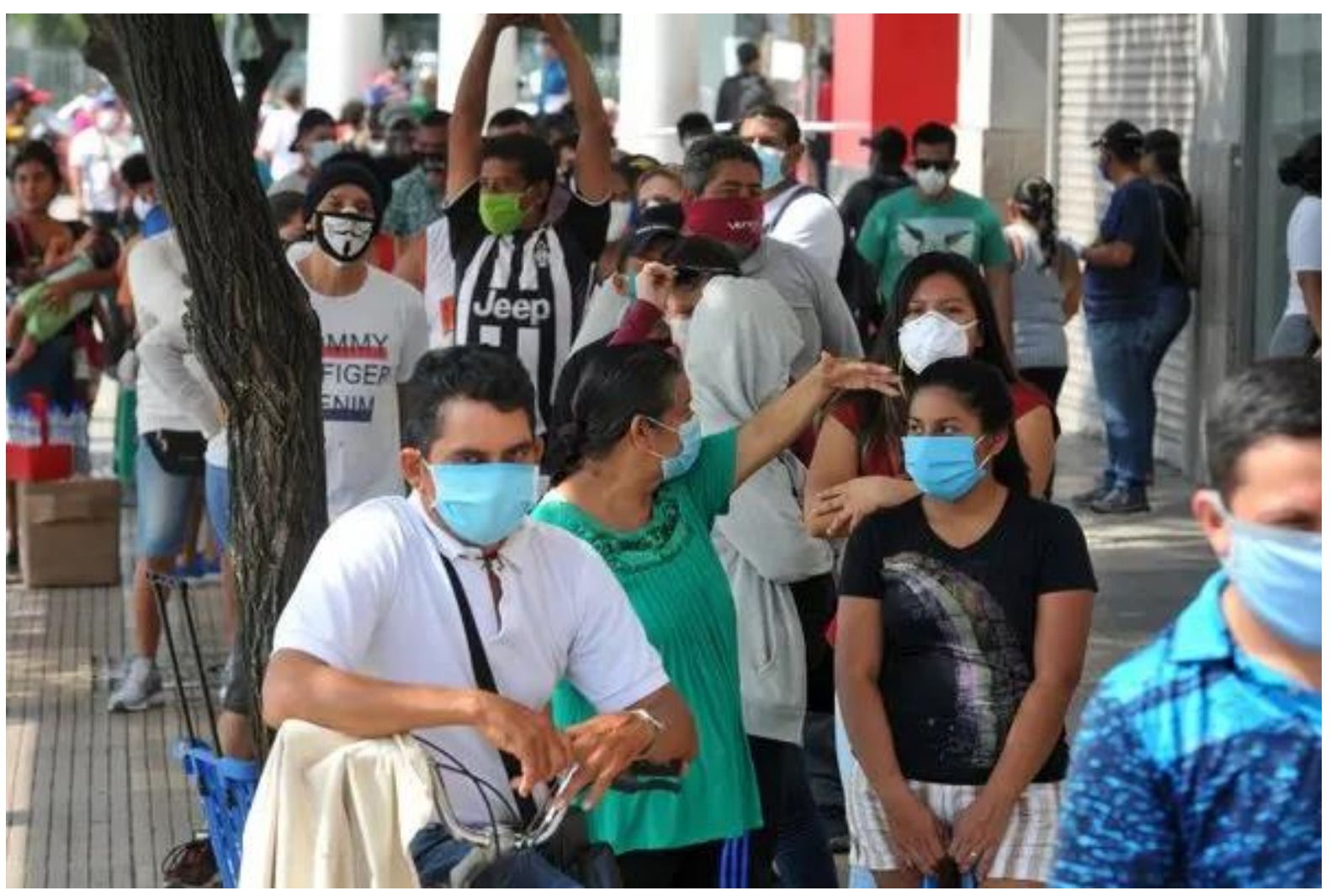

